\title{
Living with periodontitis
}

Nicola X. West

Guest Editor of the Periodontics Themed Issue, Periodontology, Bristol Dental School, UK

The $B D J$ Upfront section includes editorials, letters, news, book reviews and interviews. Please direct your correspondence to the News Editor, Kate Quinlan at k.quinlan@nature.com. Press releases or articles may be edited, and should include a colour photograph if possible.

I am honoured to be the editor of this themed issue of the BDJ dedicated to periodontal diseases and associated systemic conditions, and, importantly, reflecting on 'living with periodontitis' from a patient's perspective. It would not have been possible to compile this edition without the tremendous contributions by my friends and colleagues, to all of whom I extend a huge thank you. The British Society of Periodontology (BSP) is our perio family in the UK and I am delighted to include articles from some of its key players. Our extended family is the European Federation of Periodontology (EFP), members of which have also contributed to the papers in this edition. I was humbled when, earlier this year, I was elected Secretary General of the EFP for 2019. A mark of the inclusivity of the EFP with absolutely no mention of BREXIT!

The bedrock of successful dental treatment is periodontal stability, achieved in the main, by good plaque control. The majority of periodontal diseases are totally preventable, yet $50 \%$ of the world's population suffers from periodontitis, and $60 \%$ for those over 65 years. Indeed, severe periodontitis is the sixth most prevalent disease of mankind. Following toothbrushing people often remove less than $50 \%$ of their plaque, and if asked to repeat the brushing, they will miss the same areas of plaque again. As clinicians, we need to think of novel approaches to engage and support people to take ownership and management of their periodontal condition with excellent oral hygiene.

Evidence for the association between periodontal disease and systemic conditions is growing year on year. Well-established links between periodontal disease and, inter alia, diabetes, cardiac lesions and, more recently, rheumatoid arthritis and dementia are eloquently discussed in this themed issue with management strategies.

One of my particular research interests is trying to understand a hypothesis for
Alzheimer's disease; we know there is a lot more going on in the brain beside amyloid plaques and tau tangles! The finger of suspicion is pointing at periodontal pathogens as a risk factor for Alzheimer's disease. Both conditions have a similar pathology in that they are age related, chronic diseases that progress slowly over decades, characterised by low grade inflammation. This ongoing research has built up momentum and will hopefully elucidate causality between periodontal disease and Alzheimer's disease.

Literature has paid very little attention, as yet, to patient perception of periodontal disease. However, a fundamental goal which clinicians must strive for is not only a good clinical outcome from treatment, but also a

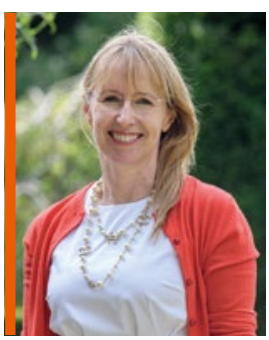

\section{'As clinicians, we need to think of novel approaches to engage and support people'}

presidents and executives of our learned societies, young general practitioners, specialists and academic leaders in the field, and most importantly patients, have made valuable contributions to this exciting edition, demonstrating the breadth and depth of the subject.

What is the future for the management of periodontal diseases? I was fortunate to be involved in 2017 World Workshop on the Classification of Periodontal and Peri-implant Diseases and Conditions. The British Society of Periodontology has been a world leader in developing and implementing guidelines to introduce this new classification for the benefit of our clinicians and patients in the UK.

Life as they say, is short and, therefore, we need to enjoy it. My vision for the future is for positive outcome from the patient's perspective. Papers in this issue explore the patient's perspective of living with periodontitis and the effect on quality of life, which I hope you will enjoy as well as furthering your knowledge of the patient's view of the professional management of their condition. Undertaking periodontal treatment for patients in a busy NHS practice has always been challenging and I have included two papers, one from the North of England and the second regarding foundation dentists in the South West of England, to show that it is possible to stabilise a periodontally susceptible patient, with proven success.

I have asked for comments and thoughts from my friends and colleagues that support the art, science and future of periodontal management, for inclusion in this issue. Past improved oral health for all. Bleeding gums are not healthy! The consequential benefits of excellent oral health include improved communication, eating and, importantly, laughing and smiling. If we can't smile our quality of life is poorer, whereas an attractive smile is universally accepted as a sign of success and happiness. A happier person is a healthier person and this speaks louder than words.

I hope we have inspired you in this themed edition of the $B D J$, and furthered your knowledge. I would like to thank the person who inspired me many years ago (and still does) in this wonderful subject, Professor Martin Addy, and my friends and colleagues whom I work with to promote periodontal health for a better life.

https://doi.org/ 10.1038/s41415-019-0838-x 